\title{
Tenofovir Disoproxil Fumarate: New Chemical Developments and Encouraging in vitro Biological Results for SARS-CoV-2
}

\author{
Giuliano C. Clososki, ${ }^{\circledR *, a}$ Rafael A. Soldi, ${ }^{a, b}$ Rodrigo M. da Silva, ${ }^{c}$ Thais Guaratini, ${ }^{c}$ \\ José N. C. Lopes, ${ }^{c}$ Pâmela R. R. Pereira, ${ }^{\circledR a}$ João L. C. Lopes, ${ }^{a, d}$ Thiago dos Santos, ${ }^{a}$ \\ Ronaldo B. Martins, ${ }^{e}$ Cristina S. Costa,${ }^{e}$ Andréia $N$. de Carvalho, ${ }^{e}$ Luis L. P. daSilva, ${ }^{e}$ \\ Eurico Arruda ${ }^{*, e}$ and Norberto P. Lopes ${ }^{\circledR} *, a$ \\ ${ }^{a}$ Núcleo de Apoio a Pesquisa em Produtos Naturais e Sintéticos (NPPNS), \\ Departamento de Ciências BioMoleculares, Faculdade de Ciências Farmacêuticas de Ribeirão Preto, \\ Universidade de São Paulo, 14040-903 Ribeirão Preto-SP, Brazil \\ ${ }^{b}$ Núcleo de Pesquisa, Centro Universitário Facol (UNIFACOL), \\ 55612-650 Vitória de Santo Antão-PE, Brazil \\ 'Lychnoflora Pesquisa e Desenvolvimento em Produtos Naturais LTDA, \\ Ângelo Mestriner, 263, 14030-090 Ribeirão Preto-SP, Brazil \\ ${ }^{d}$ Avita Produtos Químicos e Farmacêuticos LTDA, Supera Parque, \\ 14056-680 Ribeirão Preto-SP, Brazil \\ ${ }^{e}$ Departamento de Biologia Celular e Molecular e Bioagentes Patogênicos, \\ Faculdade de Medicina de Ribeirão Preto, Universidade de São Paulo, \\ 14049-900 Ribeirão Preto-SP, Brazil
}

\begin{abstract}
The recent emergence of severe acute respiratory syndrome coronavirus 2 (SARS-CoV-2) has led society to live with a serious public health problem. In this sense, repositioning of antiretrovirals has captured the attention of the scientific community. Tenofovir disoproxil fumarate (TDF) is an antiretroviral compound that is used to treat acquired immune deficiency syndrome (AIDS) and hepatitis B. In this short report, we present a scale-up investigation of TDF by in situ infrared spectroscopy monitoring and a forced degradation study to describe a new degradation product. Finally, we have evaluated TDF in vitro for SARS-CoV-2 for the first time foreseeing the using of this medicine in pre-clinical and clinical investigations for the COVID-19 (coronavirus disease 2019) treatment.
\end{abstract}

Keywords: tenofovir disoproxil fumarate, scale-up studies, putative metabolites, SARS-CoV-2, COVID-19, infrared spectroscopy, electrospray ionization mass spectrometry

\section{Introduction}

Revealed in December 2019 in Wuhan, Hubei Province, China, severe acute respiratory syndrome coronavirus 2 (SARS-CoV-2) is associated with a continuous outbreak of atypical pneumonia, designated COVID-19 (coronavirus disease 2019). ${ }^{1}$ It is a rapidly spreading virus, and providing timely treatment of patients with this disease is essential. ${ }^{1}$ Developing new drugs from the beginning represents an impractical initiative as an

*e-mail: gclososki@fcfrp.usp.br; eaneto@ fmrp.usp.br; npelopes@fcfrp.usp.br

In memorian of Prof Suely Lins Galdino. immediate solution. In the midst of anxiety, repositioning drugs is a promising strategy. ${ }^{2}$

Tenofovir disoproxil fumarate (TDF) is an antiretroviral compound that is applied to treat patients with acquired immune deficiency syndrome (AIDS) and hepatitis B. TDF, a pro-drug of tenofovir, works as a nucleoside analogue reverse transcriptase inhibitor and was designed to improve absorption and cell permeability. ${ }^{3}$ The world press have been reported on advances with remdesivir, a medication of the same class as TDF, in accelerating the recovery of COVID-19 patientes, by virus RNA polymerase inhibition. ${ }^{4}$ Although we do not have complete and conclusive clinical data that suggest a mechanism 
of action for the use of tenofovir and its analogs to treat patients with COVID-19, the attempt to reposition is a valid strategy that can reduce the time that is necessary to develop a treatment or an adjuvant.

This initiative has stimulated several research groups to work on scale-up and optimizations of the protocols. We are engaged on this, and also decided to investigate TDF as one of the active pharmaceutical ingredients (APIs) against COVID-19 infection. Thus, we report our results on TDF preparation from adenine in a pilot plant-scale through Fourier transform infrared spectroscopy (FTIR) in-line monitoring. To reinforce the safe use of TDF, we have conducted a forced degradation study. Finally, we have evaluated the pure samples in vitro to inhibit SARS-CoV-2 assay looking to support the repositioning of this API.

\section{Experimental}

The synthetic strategy was based on a previously published bench work, ${ }^{3,5}$ and all the experimental details and modifications are described in the Supplementary Information (SI) section. Scale-up studies were performed in a Büchiglasuster MiniPilot R15 multipurpose pilot reactor system equipped with a Huber Unistat 510 Dynamic temperature control system. The reactions were monitored in situ by infrared spectroscopy in the frequency range of 2500-650 $\mathrm{cm}^{-1}$; a ReactIR $15^{\circledR}$ Mettler Toledo spectrometer connected with an attenuated total reflectance (ATR) fiber probe was employed. Racemic $\mathbf{4}$ was used in the scale-up studies.

The forced degradation study was carried out under more extreme conditions. The stress conditions employed in this study were modified from a previous work ${ }^{6}$ and standardized, and they are presented in the SI section. The liquid chromatography-electrospray ionization-mass spectrometry (LC-ESI-MS) protocol is also depicted in the SI section.

To test whether TDF or tenofovir affected SARS-CoV-2 in vitro infection, sub-confluent monolayers of Vero CCL-81 cells (American Type Culture Collection, Manassas, VA, USA) were treated with $3 \mu \mathrm{M}$ TDF or left untreated for $24 \mathrm{~h}$, which was followed by incubation of the monolayers with SARS-CoV-2 stocks (multiplicity of infection (MOI) 1) on a rocker at $4{ }^{\circ} \mathrm{C}$ for $2 \mathrm{~h}$, for virus adsorption. The monolayers were washed with ice-cold phosphate buffered saline (PBS) and incubated with $0.5 \mathrm{~mL}$ of Dulbecco's modified Eagle medium (DMEM) (Life Technologies, Carlsbad, USA) without fetal bovine serum (FBS). The latter incubation was conducted at $37^{\circ} \mathrm{C}$ and in $5 \% \mathrm{CO}_{2}$, in the absence or presence of $3 \mu \mathrm{M}$ TDF. Supernatants from triplicate monolayers were collected
$48 \mathrm{~h}$ after infection and had their total RNA extracted with Trizol $^{\circledR}$, to quantify the viral genome load by one-step TaqMan real-time quantitative reverse transcriptasepolymerase chain reaction (1-step RT-qPCR). The SARS-CoV-2 genome was detected by using primer-probe set for 2019-nCoV_N1 gene, according to the USA-CDC (Centers for Disease Control and Prevention) protocol. ${ }^{7}$ 1-Step RT-qPCR for RNAseP, as housekeeping gene, was done for all the samples. ${ }^{8}$ All the qPCR assays were carried out on the Step-One Plus real-time PCR thermocycler (Applied Biosystems, Foster City, CA, USA). Briefly, after Trizol $^{\circledR}$ extraction, $100 \mathrm{ng}$ of each RNA sample were used in the one-step RT-qPCR, with N1 primers and TaqPath 1-Step RT-qPCR Master Mix (Applied Biosystems, Foster City, CA, USA). One-step RT-qPCR was accomplished in a final volume of $20 \mu \mathrm{L}$ by employing $100 \mathrm{ng}$ of RNA, $20 \mu \mathrm{M}$ forward and reverse N1 primers, $5 \mu \mathrm{M}$ N1 probe, and $5 \mu \mathrm{L}$ of TaqPath 1-Step RT-qPCR Master Mix (Applied Biosystems, Foster City, CA, USA). The following parameters were used: $25^{\circ} \mathrm{C}$ for $2 \mathrm{~min}, 50{ }^{\circ} \mathrm{C}$ for $15 \mathrm{~min}$ for RT incubation, $95^{\circ} \mathrm{C}$ for 2 min for enzyme activation, followed by 45 cycles of $94{ }^{\circ} \mathrm{C}$ for $5 \mathrm{~s}$ and $60{ }^{\circ} \mathrm{C}$ for $30 \mathrm{~s}$, with final soaking at $10^{\circ} \mathrm{C}$. Variation in the cycle thresholds $(\triangle \Delta \mathrm{CT})$ of qPCR amplification of the virus genome was used to analyze virus yield in the tests.

Cytotoxicity and cell viability after treatment with tenofovir or TDF was determined by using the alamarBlue Cell Viability reagent (Thermo Scientific, Waltham, USA); the manufacturer's instructions were followed. Briefly, monolayers of Vero CCL-81 cells in a 96-well plate were left untreated or were treated (in triplicate) with tenofovir or TDF at 3,10,30,90, or $270 \mathrm{mM}$ for $24 \mathrm{~h}$. After this time, the cells were washed with PBS, and then they were re-incubated with DMEM without FBS and with the respective compound (tenofovir or TDF) concentration $(3,10,30,90$, or $270 \mathrm{mM})$ for $48 \mathrm{~h}$ to simulate infection conditions. The alamarBlue reagent was added at $10 \%$ of the culture volume, and the cells were further incubated at $37^{\circ} \mathrm{C}$ for $4 \mathrm{~h}$. Fluorescence was measured on a SpectraMax (Molecular Devices) microplate reader; the excitation and the emission wavelength was 530 and $590 \mathrm{~nm}$, respectively. The mean of the cell control (untreated) was set as $100 \%$, and the cell viability of each treatment condition was calculated relative to this value.

The statistical data are shown as mean \pm standard error of the mean (SEM) of experiments done in triplicate and significance was analyzed by one-way analysis of variance (ANOVA) with Bonferroni's corrections. The $P$ values are labeled as: $* * P<0.01$; $* * * P<0.001$. Differences were considered statistically significant at $P<0.05$. Data were plotted and analyzed using GraphPad Prism 5.0 software. ${ }^{9}$ 


\section{Results and Discussion}

In 2010, Ripin and co-workers ${ }^{3,5}$ reported an important optimization in the TDF manufacture process. We chose this approach for our scale-up studies (up to $1 \mathrm{~kg}$ of the starting materials) of the TDF based on the FTIR-ATR in-line monitoring strategy ${ }^{10-12}$ that supported some modifications to the process on a pilot scale (Scheme 1). For example, by monitoring the consumption of substrate $\mathbf{3}$ (bands at 1805 and $1048 \mathrm{~cm}^{-1}$ ) and the formation of 4 (bands at 1592 and $1297 \mathrm{~cm}^{-1}$ ), we found that substitution of $\mathrm{NaOH}$ for $\mathrm{K}_{2} \mathrm{CO}_{3}$ significantly accelerated the reaction between adenine and propylene carbonate in the first step of the route, to give the desired alcohol 4 in higher yield. Moreover, in the second reaction step, application of chemical and glassware drying techniques allowed us to use a reduced amount of the base, which afforded phosphonate diester $\mathbf{6}$ with improved yield. Furthermore, monitoring the bands at 1254 and $1685 \mathrm{~cm}^{-1}$ effectively helped to control the hydrolysis of 6 throughout step 3 of the process, which was completed within a shorter time to afford tenofovir 7 in $82 \%$ yield. In contrast, intrinsic characteristics of the last step of the process (i.e., the need for low concentration) made reliable FTIR-ATR in-line readings difficult, so we monitored the reactions that led to $\mathbf{1}$ from $\mathbf{7}$ by offline high-performance liquid chromatography (HPLC).

Forced degradation assays showed two known degradation products, as represented by the total ion chromatogram of TDF oxidation in peroxide condition (Figure S20, SI section). Tenofovir ( $\mathrm{m} / \mathrm{z}, 288)$ also emerged as degradation product (DP) from TDF, and it was more evident in acidic and alkaline hydrolysis conditions, as already described. ${ }^{13}$ The third known DP was identified as tenofovir monosoproxil, also considered an impurity by the International Pharmacopoeia of the World Health Organization (2019). ${ }^{14}$ In addition, the most intense signal in the mass spectrum of the known DP with retention time of $23.7 \mathrm{~min}$ arose at $\mathrm{m} / \mathrm{z} 536$ (Figure S21d, SI section). The molecular mass of this DP corresponded to an increase of $16 \mathrm{Da}$ in the TDF molecular mass, suggesting that an oxygen atom was introduced into the TDF chemical structure. A detailed analysis of gas-phase chemistry during ESI-MS/MS analysis has been accomplished to suggest the DP structures and to define safety protocols. ${ }^{15}$ In this way, a detailed analysis of TDF ESI-MS/MS (Figures S22 and S24, SI section) revealed the presence of some initial fragments with larger mass that corresponded to simple neutral eliminations. The key fragmentation pathway started with the ion at $m / z$ 270: an internal rearrangement with the loss of the two side chains and the reaction of only one oxygen atom occurred (Figure S24, SI section). The next step was $\mathrm{PO}_{2}$ elimination by anchimeric assistance, which was followed by $\mathrm{H}_{2} \mathrm{CO}$ elimination. The oxidative products showed the same fragmentation pathway with 16 more mass units, which suggested oxidation at the amino purine moiety (Figure S24, SI section). This DP has never been reported and was only observed for the oxidation in peroxide condition, which reinforces the importance of scaling up the oxidative reaction for complete characterization of the molecule.

As a preliminary analysis to investigate TDF as a possible candidate for drug repositioning against<smiles>Nc1ncnc2[nH]cnc12</smiles><smiles>CC1COC(=O)O1</smiles><smiles>CC(O)Cn1cnc2c(N)ncnc21</smiles>

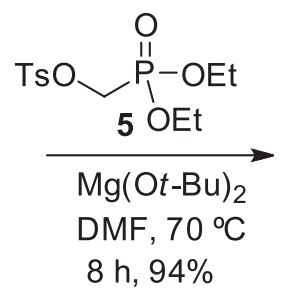<smiles>CCOP(=O)(COC(C)Cn1cnc2c(N)ncnc21)OCC</smiles>

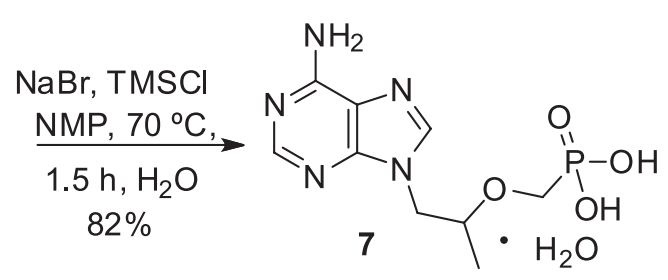

i.<smiles>CC[R15](N)(N)OC(=O)OCCl</smiles>

ii. Fumaric acid, isopropanol, $70^{\circ} \mathrm{C}, 3 \mathrm{~h}, 66 \%$<smiles>CC(C)OC(=O)OCOP(=O)(COC(=O)OC(C)C)OCOC(C)Cn1cnc2c(N)ncnc21</smiles>

Scheme 1. Synthetic route that was used to prepare $\mathbf{1}$ on a pilot scale. 


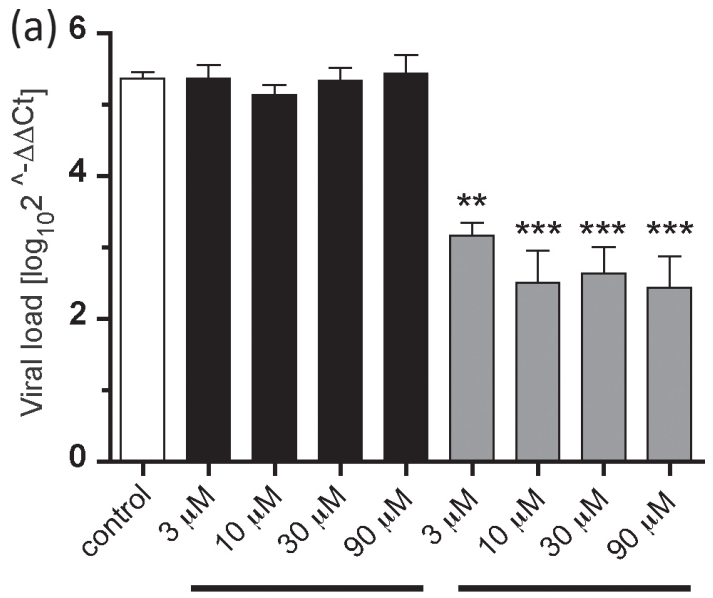

Tenofovir

TDF

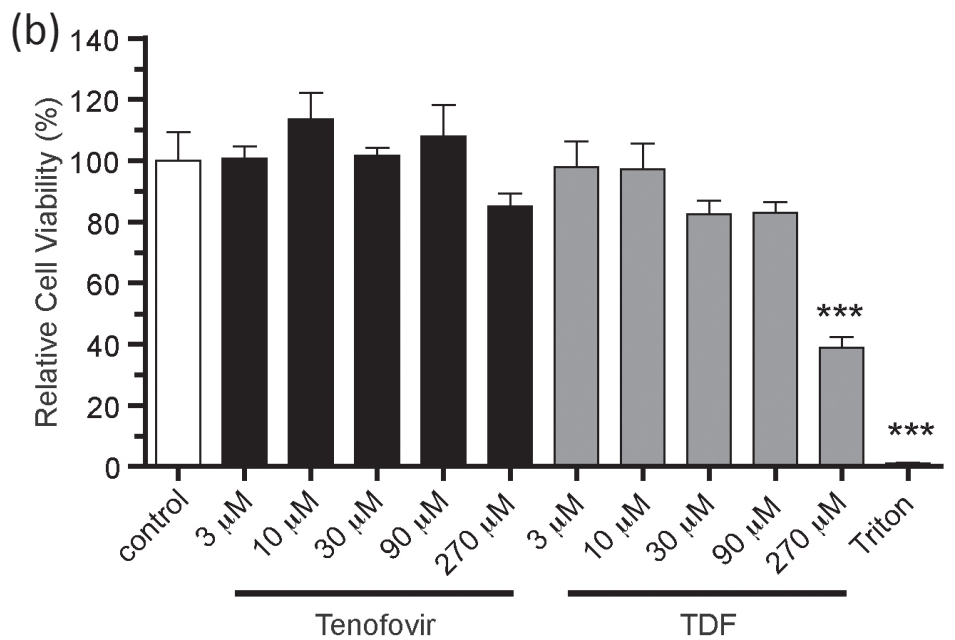

Figure 1. (a) TDF treatment partially inhibits SARS-CoV-2 replication in cell culture. Vero cells untreated (control) or pretreated with either tenofovir or TDF for $24 \mathrm{~h}$ at the indicated concentrations were infected with SARS-CoV-2 (MOI 1). After infection, cells were left untreated (control) or were further treated with the drugs at the same concentrations for $48 \mathrm{~h}$, when supernatant of infected cells were harvested and processed for qPCR; (b) alamarBlue cell viability assay showing that tenofovir or TDF are not toxic to cells at the concentration and incubation times used in (a). Cells treated for $1 \mathrm{~h}$ with $0.1 \%$ Triton, prior to the assays, were used as positive control for cytotoxicity. $* * P<0.01$; *** $P<0.001$ (one-way ANOVA with Bonferroni's corrections).

SARS-CoV-2 infection, we tested how treatment with this drug affected viral replication in cell culture. The qRT-PCR results showed that treatment with TDF between 3 and $90 \mu \mathrm{M}$ reduced the amount of released viral genome by approximately 15-fold (Figure 1a), which indicated that viral particle production declined significantly. In contrast, treatment with tenofovir in the same concentration range did not inhibit viral genome production (Figure 1a). Importantly, none of the drugs showed detectable cytotoxicity at these concentrations and incubation conditions (Figure 1b). Consistent with our results, TDF is much more active against human immunodeficiency virus (HIV) replication in MT-2 T-cells and peripheral blood mononuclear cells than tenofovir ${ }^{16,17}$ because TDF presents faster intracellular uptake and efficient accumulation ( $>1000$-fold higher) in the active form tenofovir diphosphate. ${ }^{16}$ Tenofovir and TDF metabolites inhibit HIV replication by acting as DNA chain terminators due to their capacity to bind the viral reverse transcriptase and to compete with the natural substrate deoxyadenosine 5'-triphosphate during viral complementary DNA synthesis. Interestingly, a recent molecular docking study ${ }^{17}$ indicated that tenofovir tightly binds to SARS-CoV-2 RNA-dependent RNA polymerase (RdRp), suggesting that this drug may also potentially inhibit the activity of this enzyme. Additionally, we have performed a docking study with the recently published ${ }^{4}$ cryogenic electron microscopy (cryo-EM) structure of SARS-CoV-2 RdRp (PDB id = 7BV2, $2.50 \AA$ ) that corroborates the binding of tenofovir to the same region occupied by remdesivir (see SI section). Although the mechanism underlying the TDF-mediated SARS-CoV-2 inhibition shown here remains to be unveiled, these results are encouraging and support additional research into the use of TDF in the treatment of patients with COVID-19.

\section{Conclusions}

In conclusion, scale-up studies on TDF based on FTIRATR in-line monitoring strategy allowed us to propose modifications to previous protocols and to control of the process, so now we are able to transfer the methodology to pharmaceutical companies to produce this API in our country. Stability studies showed a new degradation product which could be usefull for the API quality control. Finally, the biological assay indicated that repositioning TDF to treat patients with COVID-19 is promising, and we hope it can stimulate further pre-clinical and clinical trials.

\section{Supplementary Information}

Supplementary information is available free of charge at http://jbcs.sbq.org.br as PDF file.

\section{Acknowledgments}

The authors are thankful for Artur de L. L. Vaz, Daniel R. Callejon and the Supera Park team for technical and management support. The authors also gratefully acknowledge the financial support received from INCT-if, FINEP (contract 1.12.0282.04), FAPESP (2014/50265-3, 2018/14150-8, 2014/02438-6), CAPES, and CNPq. Finally, we thank FAPESP and CNPq for stimulating special programs to support rapid investigations on COVID-19. 


\section{Author Contributions}

Giuliano Clososki was responsible for conceptualization, data curation, formal analysis, funding acquisition, investigation, methodology, project administration, writing-original draft, writing-review and editing; Rafael Soldi for conceptualization, data curation, formal analysis, investigation, methodology, project administration, writingreview and editing; Rodrigo Moreira for data curation, formal analysis, investigation, methodology, validation; Thais Guaratini for conceptualization, funding acquisition, investigation, methodology, project administration, writingoriginal draft; José Norberto C. Lopes for conceptualization, funding acquisition, project administration, supervision, writing-review and editing; Pâmela R. R. Pereira for data curation, formal analysis, investigation, methodology; João Lopes for conceptualization, funding acquisition, project administration, resources, supervision, visualization, writing-review and editing; Thiago Santos for data curation, investigation, software, writing-review and editing; Ronaldo Bragança for formal analysis, investigation, methodology, writing-review and editing; Cristina Costa for data curation, formal analysis, investigation, methodology, writing-review and editing; Andreia Carvalho for data curation, formal analysis, investigation, methodology, writing-review and editing; Luis Lamberti P. daSilva for conceptualization, data curation, formal analysis, investigation, methodology, project administration, writing-original draft, writing-review and editing; Eurico Neto for conceptualization, data curation, formal analysis, funding acquisition, investigation, methodology, project administration, resources, supervision, writing-review and editing; Norberto Peporini Lopes for conceptualization, data curation, formal analysis, funding acquisition, investigation, methodology, project administration, resources, software, supervision, validation, visualization, writing-original draft, writing-review and editing.

\section{References}

1. Walls, A. C.; Park, Y. J.; Tortorici, M. A.; Wall, A.; McGuire, A. T.; Veesler, D.; Cell 2020, 181, 281.

2. Shah, B.; Modi, P.; Sagar, S. R.; Life Sci. 2020, 252, 117652.
3. Ripin, D. H. B.; Teager, D. S.; Fortunak, J.; Basha, S. M.; Bivins, N.; Boddy, C. N.; Byrn, S.; Catlin, K. K.; Houghton, S. R.; Jagadeesh, S. T.; Kumar, K. A.; Melton, J.; Muneer, S.; Rao, L. N.; Rao, R. V.; Ray, P. C.; Reddy, N. G.; Reddy, R. M.; Shekar, K. C.; Silverton, T.; Smith, D. T.; Stringham, R. W.; Subbaraju, G. V.; Talley, F.; Williams, A.; Org. Process Res. Dev. 2010, 14, 1194.

4. Yin, W.; Mao, C.; Luan, X.; Shen, D.-D.; Shen, Q.; Su, H.; Wang, X.; Zhou, F.; Zhao, W.; Gao, M.; Chang, S.; Xie, Y.; Tian, G.; Jiang, H.; Tao, S.; Shen, J.; Jiang, Y.; Jiang, H.; Xu, Y.; Zhang, S.; Zhang, Y.; Xu, H. E.; Science 2020, eabc1560.

5. Houghton, S. R.; Melton, J.; Fortunak, J.; Ripin, D. H. B.; Boddy, C. N.; Tetrahedron 2010, 66, 8137.

6. Golla, V. M.; Kurmi, M.; Shaik, K.; Singh, S.; J. Pharm. Biomed. Anal. 2016, 131, 146.

7. Nalla, A. K.; Casto, A. M.; Huang, M.-L. W.; Perchetti, G. A.; Sampoleo, R.; Shrestha, L.; Wei, Y.; Zhu, H.; Jerome, K. R.; Greninger, A. L.; J. Clin. Microbiol. 2020, 58, e00557-20.

8. Proenca-Modena, J. L.; Valera, F. C. P.; Jacob, M. G.; Buzatto, G. P.; Saturno, T. H.; Lopes, L.; Souza, J. M.; Paula, F. E.; Silva, M. L.; Carenzi, L. R.; Tamashiro, E.; Arruda, E.; Anselmo-Lima, W. T.; PLoS One 2012, 7, e42136.

9. GraphPad Prism 5.0; GraphPad Software Inc., San Diego, CA, USA, 2007.

10. Minnich, C. B.; Buskens, P.; Steffens, H. C.; Bäuerlein, P. S.; Butvina, L. N.; Küpper, L.; Leitner, W.; Liauw, M. A.; Greiner, L.; Org. Process Res. Dev. 2007, 11, 94.

11. de Souza, A. V. A.; da Silva, J. F. C.; Org. Process Res. Dev. 2013, 17, 127.

12. Skilton, R. A.; Parrott, A. J.; George, M. W.; Poliakoff, M.; Bourne, R. A.; Appl. Spectrosc. 2013, 67, 1127.

13. Havele, S.; Dhaneshwar, S. R.; Sci. World J. 2012, 894136.

14. World Health Organization; WHO Drug Inf. 2019, 33, 757.

15. Demarque, D. P.; Crotti, A. E. M.; Vessecchi, R.; Lopes, J. L. C.; Lopes, N. P.; Nat. Prod. Rep. 2016, 33, 432.

16. Arimilli, M. N.; Kim, C. U.; Dougherty, J.; Mulato, A.; Oliyai, R.; Shaw, J. P.; Cundy, K. C.; Bischofberger, N.; Antiviral Chem. Chemother. 1997, 8, 557.

17. Elfiky, A. A.; Life Sci. 2020, 253, 117592. 